\title{
Psychological and Pedagogical Problems of Computer- aided Teaching of Natural Sciences
}

\author{
https://doi.org/10.3991/ijet.v16i20.24427 \\ Salima A. Medetbayeva ${ }^{(\bowtie)}$, Nurlan K. Akhmetov \\ Abai Kazakh National Pedagogical University, Almaty, Republic of Kazakhstan \\ medetbayeva6239@murdoch. in
}

\begin{abstract}
Information has become a global inexhaustible resource for mankind, which has entered a new era in the development of civilisation. Today it is important to improve the quality of education by introducing computer technologies in chemistry classes. The purpose of the study was to develop and present the methodological foundations of the development and implementation of computer technologies in the game teaching of chemistry to improve the teaching methods. To achieve this goal, the corresponding tasks were identified, as well as methods for their solution: the analysis and comparative analysis, modelling. Results of the study: the positive and negative factors of the use of modern computer technologies in chemistry classes were identified; the principles of selecting the content of the material using information and communication technologies in teaching were characterised; the methodical foundations of the application and use of information and communication technologies when teaching chemistry were considered. It was concluded that the use of a computer in the educational process contributes to the improvement of teaching methods more than any other technical means at the teacher's disposal. The introduction of information technologies into the educational process significantly changes and ultimately increases the effectiveness of teaching. The practical significance of the study is conditioned by the fact that the methodical foundations of the use of information technologies in chemistry class presented in the paper can be applied in schools and other educational institutions.
\end{abstract}

Keywords - modern technologies, computerisation, gamification, teacher, student

\section{Introduction}

The progression of the "microcomputer revolution" made personal computers more affordable. In addition, technical parameters and software are constantly being improved, which makes them an increasingly attractive and effective research tool, creating real opportunities for using the latest information technologies in the work of teachers. Admittedly, a personal computer is not only an indispensable tool for editing and printing any work, but also a convenient tool for the implementation of "fine" research methods, which allows optical input of visual material into the computer memory and 
much more [1]. Today, a teacher must perfectly master not only the content of the subject, the method, means and forms of organising the educational process, but also modern teaching technologies. The main principles of modernisation of the education system in Kazakhstan are: updating the content and improving the quality of education; ensuring access to education for various social strata and geographically remote population groups; increasing the social status and professionalism of teachers [2-4]. Modernisation is primarily aimed at creating a personality-oriented education system. Such a system assumes the creation of favourable conditions for each student for independent work, the assimilation of didactic material at a convenient pace for each student, and the possibility of manifesting the acquired skills. The education system has now undergone a number of serious changes: attention was paid to a versatile approach to schoolchildren and students, the use of modular learning, the use of information technology (IT) tools in the educational process [5-8].

Throughout the life of an educational institution, one and the same task is being solved, namely, increasing the effectiveness of education. Conventionally, this task is solved by making all sorts of improvements, such as changing the number of hours in the curriculum, using various visual aids. From the standpoint of the didactic system for the implementation of the educational process, the direct communication channel is constantly being improved [9]. At the same time, through the feedback channel, information about the quality of the assimilation of the material from time to time comes from the student to the teacher. The most promising for improving the feedback channel in this situation is the introduction of various computer technologies into the educational process - highly effective interactive multimedia programmes and appropriate equipment [10].

Currently, computer technologies are increasingly being introduced into the educational process of a school or university. With the use of computer technologies in chemistry classes, the motivation for learning increases and the efficiency of independent work increases. The computer opens up completely new possibilities in terms of education, learning activities, and creativity of students [11]. Researchers found that the student remembers a quarter of visual information, a quarter of audio information, more than half of simultaneous audio and visual information. Furthermore, students remember a third of what they see, hear, and do at the same time. A person has 5 main channels of perception of the surrounding world, of which up to $90 \%$ of all information received by a person (approximate data) passes through the visual channel, through the ear canal - up to $9 \%$, and on the remaining 3 channels (smell, touch, taste) accounts for about $1 \%$ of the incoming information. It is the use of computer technologies in the classroom that allow students to more fully use all channels of information perception $[12 ; 13]$.

The purpose of the study is to develop and present the methodological foundations of development and implementation of computer technologies in chemistry classes to improve teaching methods. 


\section{$2 \quad$ Materials and methods}

In the furtherance of this goal, the following research problems were identified, for the solution of which the appropriate methods of scientific knowledge were chosen:

1. Study of the positive and negative aspects of the use of information and communication technologies in education. For this purpose, the comparative analysis was carried out, the point of which is to compare individual social phenomena and processes to determine their common features and differences. In this case, one social phenomenon was investigated, namely the use of information and communication technologies (ICT) during chemistry classes, but from different positions - positive and negative. Thus, a comparison was made between two views on the use of ICT in the learning process in an educational institution.

2. Acquaintance with the principles of selection of the content of the material using ICT in teaching. To study these principles, an analysis was performed, which allowed: to describe in detail each principle; to compose its characteristics; consider the main methods and means of its implementation in training.

3. Presentation of the methodological foundations for the use of information and communication technologies during chemistry classes. To accomplish this task, a modelling was used, which allowed replacing real objects with their conditional examples or analogues. The modelling method describes the structure of an object, as well as the process of its functioning and development. In this study, the modelling method was used to show how modern technologies can be used in a chemistry class.

The main criterion for the effective use of computer-aided teaching technologies is the need to integrate them smoothly into the conventional education system and determine the optimal ratio of different forms of teaching. For successful implementation in the educational process, computer technologies must be included in the curriculum; implement the functions of informing, training, and monitoring; to stimulate the cognitive activity of schoolchildren and students in the process of studying educational materials; provide multi-level and multi-component knowledge.

At the same time, the choice of computer technologies and their content should be based on the structural and logical transition from reproduction to research in the study of the academic subject. In this case, students master new ways of information processing, new ways of thinking. Information technologies that perform managerial, regulative, teaching, and developmental functions can be attributed to the most important means of the intellectual development of students.

\section{Results and discussion}

The educational system is faced with the problem of how to organise work on the introduction of ICT in the chemistry classes and to increase the interest of schoolchildren/students in this subject. To tackle this problem, the education system needs to be more informative. It should ensure the development of new knowledge and skills that the students will need in the information environment, as well as a new, comprehensive 
and informational worldview. The process of teaching students using computer technologies can be effective if: it reveals theoretical approaches to the use of ICT in teaching; practical methods of using ICT will be analysed; methodological bases of using computer technologies in chemistry classes will be developed and used [14-17].

Human play activity has 3 levels of development: professional play, amateur play, and training play. Moreover, all levels of the game have not only external forms of organisation and functioning, but also their own internal techniques and methods of implementation. From this position, the game in the educational process is both a form and a method of teaching - a completely independent didactic category. Namely, it is an interconnected technology of joint teaching and learning activities of teachers and students, and simply children and adults [18]. When describing the didactic principle of visibility, the question inevitably arises of how and by what means it is possible to implement these types of visibility in practice. There are several such ways: for example, in terms of the way of expression, visual clarity can be graphic, illustrative, verbal, on-screen. In turn, illustrative visual clarity can be thematic, situational, fictional, etc. With the advent of new information technologies, an integrated way of implementing the principle of visibility has become the main one. Multimedia has become a common way of expressing the principle of visibility. Therefore, speaking of teaching aids, it is important to determine the type and form of visualisation that are used in the development of didactic tools. In turn, the type and form of visualisation largely depends on its natural and didactic value $[19 ; 20]$.

Modern information technologies open up access for students to non-conventional sources of information, increase the efficiency of independent work, open up completely new opportunities for creativity, the acquisition and consolidation of various skills [21]. Computer technologies open up great opportunities for rethinking teaching methods and techniques. The computerisation of education should, first of all, contribute to the solution of pedagogical problems. Informatisation allows moving from an authoritarian school or university to joint pedagogy, where the teacher and the student, along with information resources, become partners with the leading role of a teacher. Libraries should be converted to media libraries and media centres with a special role to play in facilitating this interaction. Special attention should be paid to a number of social consequences of the computerisation of the educational process. The use of ICT in the educational process significantly changes the role and place of the teacher and the student in the system "teacher - instructor in chemistry - student". ICT is not only a link between teacher and student. Change in the means and methods of teaching leads to a change in the content of educational activity. The learning activity, in turn, becomes more independent and creative, contributes to the implementation of an individual approach to teaching.

The content of the teacher's activity also changes. The teacher ceases to be just a "reproducer" of knowledge, becoming the creator of a new teaching technology. This, on the one hand, increases teacher's creative activity, and on the other, requires a high level of technological and methodological training [22]. In addition, it is a new technique that makes the most of the student's time. This is, first of all, the effectiveness of training [23]. The presentation of the material should be organised in such a way that all sensory organs are involved in the training. Information technologies of teaching 
allow the teacher to use both certain types of educational work, and any set of them to achieve the goals of teaching [24]. Therefore, the use of ICT teaching methods is aimed, first of all, at the integration of all types of educational activities and preparation of students for life in the information society.

The principles of visibility, awareness, and activity of the student, accessibility and appropriateness, taking into account age and individual characteristics, regularity and consistency are considered the basic principles of didactics. The basic principles also include principles of a scientific nature, the relationship between theory and practice, teaching and education. The study considers them from the standpoint of computer technology. Conventional teaching methods, as a rule, actively use the principles of visibility, but everyone who participates in the educational process knows how laborious it is to implement it. And most importantly, such methods have limited opportunities for presenting theoretical knowledge. Basically, new opportunities in this regard are given by information technologies that allow displaying the basic laws and patterns of the known, hidden from direct perception. Nowadays, various types of electronic visualisers are actively used in the field of chemistry, physics, etc. Thus, it is possible to visualise not only what is directly perceived by the senses, but also what is expressed by abstract laws and models [25].

The use of modern information technologies allows completely replacing outdated technical teaching aids - television, video and audio recorders, tape recorders, slide projectors, overhead projectors and cinema installations. This eliminates the need for tables that are inconvenient to store and categorise. The image on the tables, as well as all the contents of audio and video cassettes, can be easily converted into digital format and stored in the computer's memory and quickly reproduced if necessary [26]. As a result of the use of teaching software and pedagogical tools, the learning process becomes individual. Each student studies the material according to their own plan, i.e. according to their individual perception abilities.

The principle of accessibility and expediency of training boils down to the fact that the studied material was available due to the degree of complexity, but at the same time required the use of mental and spiritual forces for its assimilation. This essential didactic principle is very difficult to implement using conventional teaching methods. However, with the help of computers, it became possible to differentiate dialogues with students depending on their preparation, speed, and quality of assignments. Modern programmes allow generating tasks of increasing complexity, with adequate motivation. When working with such a programme, the student will choose tasks that require mental stress. The principle of awareness and activity assumes that the subject of educational activity is a schoolchild or a student. This is a new technique that allows implementing the idea of self-education, that is, the student has a motivated approach to the educational process, understands what, how, and why he / she does it. Thus, the analysis of conventional didactic principles shows that new information technologies create conditions for their full implementation [27;28].

ICT are able to solve many pedagogical problems, open up completely new opportunities for creativity, acquire and consolidate professional skills, and also allow introducing completely new forms and methods of teaching. The use of IT in the teaching 
contributes to its intensification and individualisation, improving the teacher's professional skills, increasing the efficiency of mastering the skills of independent knowledge extraction, developing the student's personality and preparing for a comfortable life in an information society. To introduce information technology into the educational process, the teacher must master computer skills, get acquainted with modern information technologies. The educational process requires: a personal computer; the basics of working in the Windows operating system; text editor Microsoft Word; work with PowerPoint; work with media resources.

Children are especially delighted to welcome all the latest technical progress. Admittedly, the curiosity and high cognitive activity of schoolchildren / students must be used for the purposeful development of their personality. The use of new information technologies in the didactic process allows directing the intellectual potential of the student to positive development. Otherwise, the craving for knowledge will dry up with meaningless spending time on the Internet. In classes under the guidance of a teacher, students can learn to use computer technology for educational purposes. This leads to the comprehensive development of intelligence, mastering methods of obtaining information to solve educational and then production problems, and acquiring skills that will help to continue learning throughout life [29]. The use of a computer in the classroom should be purposeful and methodologically sound, not a tribute to the times. A computer should not be used where other tutorials are more effective. ICT should be used only when it provides a higher level of the learning in comparison with other methods. In chemistry, the use of computer technologies is effective when studying new material (presentations at lectures), in the development of skills and abilities (educational tests), as well as in practical classes in chemistry.

The use of slides during lectures provides dynamism, clarity, and a higher level and volume of information than traditional methods. When preparing material for the class, electronic textbooks and information on the Internet can be used. The use of slideshows provides a varied approach to working with different classes. For example, slides containing complex material prepared for a group learning advanced chemistry can be skipped in other groups. When editing a new slide, it is always possible to add new information or change material. In addition to lectures, the use of a computer effectively reinforces knowledge. At the intermediate stage between obtaining new information and control of knowledge, it is necessary to organise the work of students to master the subject material, mastering self-control. One of the most effective ways is to learn how to conduct tests. This exercise involves each student working individually with computer software suggested by the teacher. The student is given the opportunity to work at a convenient pace and to pay special attention to the complicated issues. And the teacher conducts individual work with students who need help. Educational test programmes are not intended to test knowledge, but for detailed study, mastery of the subject and preparation for the final test of knowledge [30].

When conducting training tests, the student is asked a question on a given topic and four answer options, only one of which is correct. To proceed to the next question in the test, the student must select the correct answer. If the student chooses the wrong answer, the programme opens a slide with the theoretical part of the topic using a hyperlink, which contains information about the correct answer. When working with a 
curriculum that helps close knowledge gaps and does not punish a wrong answer with a lower grade, students experience positive emotions, which is very important for the successful assimilation of the material.

The study of chemistry is different from other disciplines because it involves experimentation. By organising practical exercises, the computer can become an effective assistant for the teacher. Of course, conducting experiments in a laboratory has undeniable advantages, but when studying toxic substances (benzene, halogens, etc.), the virtual world allows conducting a chemical experiment without endangering the health of students. During the class, each student works with the slides individually, with the opportunity to review the video of the experiment.

Making slides is an interesting creative process that enriches the teacher's professional experience. Admittedly, preparing classes using IT is a creative process, because the search and systematisation of information takes a lot of time. The implementation of these tasks requires, first of all, the readiness of the teachers to solve this problem. The labour invested is accumulated in the form of a whole series of lessons and master classes, which make up the intellectual abilities of the teacher. And the best reward is the growing interest of children in the subject, the joyful anticipation of each chemistry class, success at the academic competitions and at universities.

Next, the study considers the advantages of computer technologies on the example of the topic "Chemical element. Preparation of formulas of valence". The class starts with an introduction to the topic and the teacher explains the concept of a chemical element. At the next stage, students receive informational messages about the history of the appearance of symbols and names of chemical elements. Students receive news and recommendations in advance on the presentation of information, and the teacher helps in the analysis of the materials found and prepared by the students and gives recommendations on how to eliminate the gaps. A few days before class, the teacher checks the quality of the student's preparation for the presentation, special attention is paid to the content, speech and time allotted for communication. These techniques are aimed at developing independence in the search and acquisition of knowledge, recognition of the cognitive interests and intellectual abilities of students. To consolidate the material, training takes place using a computer, an interactive whiteboard and two sets of cards (the first set - with signs of chemical elements, the second - with valence).

The first stage of learning: the signs of the studied chemical elements are displayed sequentially. The teacher asks questions: What is the name of a chemical element? How is its name pronounced in Latin? What is the valence of this chemical element? (Students answer questions). The second stage of learning: the teacher alternately shows on the screen the names of chemical elements. Students write down the symbols of chemical elements and their valences in their notebooks. Thus, students took part in various forms of perception and information: saw, heard, spoke, wrote down, since the perception of information passes through several sensory organs. Consequently, associations with the studied topic are developed, the level of understanding and perception of the investigated concepts and phenomena increases. The techniques used contribute to the fullest and most profound knowledge of this subject.

The third stage of learning: on the screen, the teacher alternately shows the values from I to VII, students are asked to show one or more sheets of paper with the desired 
valence of chemical elements. Then students must find other elements in the periodic table with the same valence as hydrogen, such as magnesium, aluminium, and chlorine. The consolidation of this material by students is carried out according to the periodic system of D.I. Mendeleev, so that the student gradually learns to navigate in it. The advantage of this technique is that the teacher can see the work of the entire class and immediately assess the quality of the preparation of the entire class on the topic. This allows the teacher to navigate the further activities and understand whether it is worth starting the next topic or conduct an error analysis session [31].

The fourth stage of learning: the goal of the task is to familiarise students with the physical properties of the elements, collect information about their physical properties and repeat the symbol, valence, and names of the studied chemical elements. The teacher shows a symbol of a chemical element and a photograph of a simple substance on the screen. The photo can be taken with a digital camera or found by students on the Internet, according to the teacher's individual task, available demonstration samples of the substance are also used. Students are asked to indicate the valence and number of the group of the element. (There are elements from advanced courses at this stage, as the topic of "Periodic Law" and "Periodic Table" will be covered later). In the next class, their symbol will be used to create formulas for simple substances with regard to valence.

Educational test task: group objects according to different criteria: by valence; by electrical conductivity; belonging to one subgroup; physical state of simple substances; search for a symbol that matches an element; the elements that do not form compounds, etc. The task is performed on computers in the computer lab, and the results of the work appear on the screen immediately after its completion. Such tasks form the ability to systematise and classify elements according to various criteria. This also contributes to the assimilation of the methods of comparison, analysis, synthesis, and generalisation. Within the framework of consolidation, the task is to establish a correspondence between the symbol of a chemical element, valence and physical properties of a substance. For this purpose, the symbols of chemical elements, valences from I to VIII, as well as a list of all physical states of a substance, the presence or absence of metallic lustre, odour, etc., are imaged [32].

By making the necessary adjustments, this technique can be used at different stages of the study, explaining new material, as well as for consolidation, control, and generalisation. Such an organisation of the educational process allows teacher to simultaneously organise the active mental activity of the whole class and see the degree of assimilation of the material. In addition, the teacher assesses the level of preparation of students, whose work was observed throughout the class. When using the interactive whiteboard, students become interested in this topic, and their attitude to the topic changes from the "necessary" to "interesting". As noted above, teaching chemistry differs from other disciplines in that it requires practical work. In this case, the computer has become an effective teacher's assistant. Conducting experiments in the laboratory has undeniable advantages, but when studying toxic substances such as halogens, the virtual world allows conducting a chemical experiment without endangering health. If the classroom lacks the necessary equipment, a computer can compensate for this inconvenience. 
Participation in educational games allows the chemical classes to be emotionally rich and, therefore, more productive. For example, to develop the ability to distinguish between substances belonging to a certain class, the game "Chemical Defence" can be used. In this game various chemical elements appear on the screen and the student must shoot oxides. Educational games can also be used for extracurricular activities on the subject. In their study, N.K. Akhmetova, A.R. Nurakhmetov and A.E. Sagimbaev consider specific examples of educational games and methods of their use during chemistry classes [33]. The "Analytical Lotto" will be an excellent teaching method for students, where they can learn new information about hydrogen sulphide and acid-base classification of cations in a relaxed setting together with their classmates [34].

The use of modern game approach with computer technologies in teaching is called gamification, which helps to increase the involvement of participants in the educational process in solving applied problems. Gamification tools are various thematic websites, specialised software, authoring applications for the phone, etc. The advantages of gamification include the following: dynamics (the use of techniques that require attention, maximum involvement and quick user response), mechanics (the use of graphic elements typical of modern computer games, such as awards, titles, points, various bonuses, etc.). This contributes to the interest of the student in mastering knowledge (since it allows receiving a reward for its correct use), aesthetics (using the possibilities of modern technologies to create a game with pleasant graphics, which will contribute to the involvement of the student in the educational game process), social interaction (use of internal methods of communication, for example, chat to communicate with classmates and the teacher, as well as the online mode, allows demonstrating achievements to other participants in the learning process in real time, which will motivate others to achieve better results).

Computer technology allows demonstrating reactions with explosive or toxic substances, rare or expensive reagents, processes that go too fast or too slow, which is impossible to implement in a classroom environment. For example, when studying electrochemical corrosion, students can see the mechanism of this extremely slow process in a matter of minutes. Computer simulation turns out to be indispensable in the study of chemical processes, direct observation of which is unrealistic or difficult. Such an example is the consideration of the process of electrolytic dissociation, the study of the ion exchange reaction, where the processes occurring in a solution between ions are clearly shown in motion.

The use of visual aids (animation, video, dynamic figures, sound) will significantly expand the learning opportunities, make the content of educational materials more visual, understandable and fun. For example, the section "Chemistry in the Service of Man" brings information closer to reality. Where the teacher can clearly show the chemical processes that students see every day, but do not know about them. The use of computer technologies when teaching chemistry allows: visualising the processes under study, hidden from direct observation, with the provision of the possibility of their repetition; individualising and differentiating the learning process due to the possibility of learning at an individual pace of mastering the material; monitoring with feedback, diagnosing errors and evaluating the results of educational activities; practicing self-control and self-correction; conducting trainings in the process of mastering 
educational materials and self-education of students; popularising the manifestations of student's creativity; contributing to the development of the information culture of future specialists. Notably, the use of IT allows shifting the emphasis of teaching towards the development of each student; a real transition from simple assimilation of knowledge to developmental learning. This provides the development of the main skill of the student - the ability to study independently, learning throughout life [35]. All this is possible provided that digital educational resources are carefully selected according to the objectives and the lesson, and that the work is properly organised on one or more computers in the classroom and at home.

With all the advantages of using computer technology, it is important to note some of the disadvantages. Thus, the irrational, unjustified use of ICT can lead to the following problems: the ability to develop the culture of speech in students is limited, the ability to work with terms and writing skills are not actively developed [36]; there is an excessive algorithmisation of the mental activity of students; the state of health of students deteriorates when the permissible time for working at the computer is exceeded (according to the standards, students in grades 9 can work at the computer for no more than 30 minutes during the school day). Each teacher should carefully consider how, where and when to use the computer during classes. Provided the deliberate use of computer programmes for teaching requires constant feedback between students and the teacher, including oral (dialogue) and written (notebook) feedback [37; 38].

Computerisation affects the development of not only the cognitive, but also the motivational, emotional sphere of the individual, their self-awareness. The problems that the use of computers generates include the following: limitation of the field of creative activity of a student (a sequence of actions is rigidly set, a given result, i.e., an algorithm that narrows the space for making independent decisions by a student); imaginative thinking (the starting point of creativity) is blocked; excessive individualisation of teaching, that is, each student in the learning process carries out communication processes mainly with himself; the development in students of the unreasonable confidence in the unlimited possibilities of the computer, which border on the refusal of independent efforts; it is undesirable to use available information that harms the learning process (for example, a student, instead of writing an essay on his own, finds a finished work on the Internet or on a CD); a computer can be used not only for educational purposes, its use can lead to computer addiction (addiction to computer games and Internet addiction); health-related problems (an untrained user is recommended to continuously engage in no more than 15-20 minutes due to the harmful effects of magnetic fields, eye fatigue, etc.); expenses of additional time and labour of a teacher, since the use of computers requires high qualifications; too bright colours that are used in games affect the vision and psyche of the student, forms a distorted perception of reality, etc. Gamification of the educational process detaches from the surrounding world, promotes withdrawal into the virtual world, disrupts the development of abstract thinking, reduces or eliminates the need for reading, forms the "clipping consciousness" of a student $[39 ; 40]$.

However, there is no doubt that the use of IT in teaching contributes to better memorisation of the material and meets the requirements of the modern world. Working with multimedia technologies allows diversifying the forms of work in the classroom 
through the simultaneous use of illustrative, statistical, methodological, as well as audio and video materials. Such work can be performed at different stages of the lesson: as a way to create a problem situation; as a way to explain new material; as a form of learning; as a form of homework checking; as a way to test knowledge in the classroom. These technologies not only support the structure of the general education cycle, fully meet the requirements of the content standards, but also help to increase cognitive interest in the topic, contribute to the improvement of students' academic performance in the subject, allow students to try a new role, develop the skills of independent production activities, contribute to the creation of a successful situation for each student. Information and communication technologies work for a particular child. A student takes as much as they can study, work with an optimal pace load. There is no doubt that ICT is a new technology, and it should be more widely introduced into the educational process $[41 ; 42]$.

The use of ICT in the classroom gives the following advantages: saving time in the classroom; the depth of immersion in the material; increased motivation to learn; integrative approach to learning; the ability to simultaneously use audio, video, and multimedia materials; the ability to form the communicative competence of students, since they become active participants in the lesson at all its stages; involvement in various types of activities aimed at an active position of students who have received a sufficient level of knowledge in the subject for independent thinking, argumentation, reasoning [43]. Nowadays, the educational space is filled with computer tutorials containing different types of presentations, which are of course a good teaching tool. They guide students towards a slow pace of learning, an individual logic of learning. The significance and positive result of the model of teaching information resources are as follows: the student is in the centre of the teaching technology; cooperation is the centre of educational activities; the student has the active position in the educational process; a promising goal - to motivate students and develop their ability to individual study. To implement a new approach to learning using IT, the teacher needs to know the possibilities offered by the computer to improve the learning process at each stage $[20 ; 44]$.

Thus, at the stage of preparation for the class, the computer provides the following opportunities: create computer models to outline the lesson, topic, course as a whole; systematise the material; provide additional information to the main material; select and organise material, taking into account the characteristics of the class and individual students. During the classes, the computer allows: saving time; increasing the emotional, aesthetic and scientific reliability of teaching; optimising the learning process through interaction with different analysers; individualising learning, focusing on the most important problem of the lesson; returning to the studied material at any time; independently use the educational materials by students. At the stage of methodological verification of the didactic process, the teacher has additional opportunities: to accumulate the joint efforts of teachers; to develop, modernise and improve electronic materials; to systematically collect material; to increase the motivation to teach and learn. 


\section{Conclusions}

At different stages of the development of computer-aided teaching, different problems come to the fore. Today, the main attention should be paid not to conventional problems of psychology, such as the peculiarities of students' attention caused by the use of computers, their assimilation of knowledge and skills, etc., but to the problems of creating effective teaching system. Within such a system, the study of psychological problems performs only an auxiliary function, i.e., allows clarifying the effectiveness of a particular training system, and not the attention or thinking of students in the context of computer-aided learning. Moreover, these features are largely determined by the merits or demerits of the training system. Two main lines of computerisation can be distinguished: ensuring universal computer literacy, in this case the computer is the object of study; the use of a computer as a means of increasing the effectiveness of learning. Although these areas are not mutually exclusive (for example, in the development of computer literacy, a computer can be used as a teaching tool), nevertheless, each of them has its own characteristics and requires the solution of various psychological problems.

Modern IT training tools and electronic educational technologies allow more efficient and effective use of previously developed methods without losing their methodological value. This symbiosis of new and classical methods increases the quality and efficiency of the educational process through the implementation of the capabilities of information technology. Information technology contributes to an increase in student performance in the subject, creates a situation of success, develops the motivation and creativity of students, and also prepares them for independent cognitive activity. The use of information technologies in the educational process corresponds to the teaching of chemistry in the context of the introduction of the federal components of state educational standards.

\section{$5 \quad$ References}

[1] Williams, R. \& McLean, M. (1988). Computers at school. Moscow: Progress.

[2] Solikhin, F., Ikhsan, J. \& Sugiyarto, K.H. (2019). A need analysis in developing virtual laboratory according to the chemistry teachers. Journal of Physics: Conference Series, 1156 (1): article number 012020.

[3] Martino, M., Salvadori, A., Lazzari, F., Paoloni, L., Nandi, S., Mancini, G., Barone, V. \& Rampino, S. (2020). Chemical promenades: Exploring potential-energy surfaces with immersive virtual reality. Journal of Computational Chemistry, 41(13): 1310-1323. https://doi.org/10.1002/jcc. 26172

[4] de Mello Rezende, F.A. \& Soares, M.H.F.B. (2019). Games in chemistry teaching: A study on the presence/absence of teaching and learning theories in the perspective of Gowin's Epistemological V. Investigações em Ensino de Ciências, 24 (1): 103-121.

[5] Cunha, O.A.L., Gonçalves, J.B. \& Sarinho, V.T. (2019). Quimi-Crush: A digital game for the teaching of inorganic chemistry. Lecture Notes in Computer Science, 11863: 398-401. https://doi.org/10.1007/978-3-030-34644-7_34 
[6] Akhmetov, N.K. (1995). Theory and practice of game learning in teacher training. Almaty: Republican Publishing Office.

[7] Nazarova, T.S. (2001). The principle of visibility and teaching aids. Chemistry: Teaching Methods at School, 2: 10-15

[8] Gorodilova, N.A. (2005). Personally-oriented learning using Internet resources in chemistry. Chemistry, 15: 44-47.

[9] Lonchin, G.M. (2004). Scientific and methodological foundations of informatization and their implementation in the education system. $1^{\text {st }}$ Scientific-Practical Conference "Information Technologies in Education", 24 March 2004, Saransk, Russian Federation: MRIO.

[10] Glazkov, V.V. \& Gryzlov, S.V. (2004). Computer modeling in teaching. $1^{\text {st }}$ Scientific-Practical Conference "Information Technologies in Education”, 24 March 2004, Saransk, Russian Federation: MRIO.

[11] Korolev, L.N. \& Mikov, A.I. (2002). Informatics. Introduction to computer science. Moscow: Vysshaya Shkola.

[12] Zhurin, A.A. (1998). Elements of media education at chemistry. Chemistry at School, 1:2228.

[13] Dorofeev, M.V. (2002). Informatization of the school course of chemistry. Chemistry, 37: 2-3.

[14] Andreeva, N.D., Azizova, I.Yu. \& Stepanova, N.A. (2008). Electronic manual as an interactive teaching tool. Biology at School, 1: 48-49.

[15] Cha, J.a, Kan, S.-Y.b. \& Chia, P.W. (2018). "Spot the differences" game: An interactive method that engage students in organic chemistry learning. Journal of the Korean Chemical Society, 62(2): 159-165.

[16] Romano, C.G., Carvalho, A.L., Mattano, I.D., Chaves, M.R.M. \& Antoniassi, B. (2017). Chemical profile: A game for teaching the periodic table. Revista Virtual de Quimica, 9 (3): 1235-1244. https://doi.org/10.21577/1984-6835.20170072

[17] Samuelson, A.G. (2018). Card games and chemistry teaching organometallic reactions through card games. Resonance, 23(8): 915-923. https://doi.org/10.1007/s12045-018-0693$\underline{0}$

[18] Souza, E.C., Souza, S.H.S., Barbosa, I.C.C. \& Silva, A.S. (2018). The teaching strategy as Ludic for chemical teaching in 1 high school year. Revista Virtual de Quimica, 10(3): 449458. https://doi.org/10.21577/1984-6835.20180034

[19] Amaro-Mellado, J.L., Antón, D., Pérez-Suárez, M. \& Martínez-Álvarez, F. (2020). Gamebased student response system applied to a multidisciplinary teaching context. Advances in Intelligent Systems and Computing, 951: 329-339. https://doi.org/10.1007/978-3-03020005-3_34

[20] Brassinne, K., Reynders, M., Coninx, K. \& Guedens, W. (2020). Developing and implementing GAPc, a gamification project in chemistry, toward a remote active student-centered chemistry course bridging the gap between precollege and undergraduate education. Journal of Chemical Education, 97 (8): 2147-2152. https://doi.org/10.1021/acs.jchemed.9b00986

[21] Mellor, K.E., Coish, P., Brooks, B.W., Gallagher, E.P., Mills, M., Kavanagh, T.J., Simcox, N., Lasker, G.A., Botta, D., Voutchkova-Kostal, A., Kostal, J., Mullins, M.L., Nesmith, S.M., Corrales, J., Kristofco, L., Saari, G., Steele, W.B., Melnikov, F., Zimmerman, J.B. \& Anastas, P.T. (2018). The safer chemical design game. Gamification of green chemistry and safer chemical design concepts for high school and undergraduate students. Green Chemistry Letters and Reviews, 11 (2): 103-110. https://doi.org/10.1080/17518253.2018.1434566

[22] Ramesh, A. \& Sadashiv, G. (2019). Essentials of gamification in education: A game-based learning. Smart Innovation, Systems and Technologies, 135: 975-988. https://doi.org/ $\underline{10.1007 / 978-981-13-5977-4 \quad 81}$ 
[23] Fontana, M.T. (2020). Gamification of ChemDraw during the COVID-19 pandemic: Investigating how a serious, educational-game tournament (molecule madness) impacts student wellness and organic chemistry skills while distance learning. Journal of Chemical Education, 97 (9): 3358-3368.

[24] Edwards, B.I., Bielawski, K.S., Prada, R. \& Cheok, A.D. (2019). Haptic virtual reality and immersive learning for enhanced organic chemistry instruction. Virtual Reality, 23(4): 363373. https://doi.org/10.1007/s10055-018-0345-4

[25] Le Maire, N. (2018). "Gamification" of training activities: Feedback from a general chemistry course. Actualite Chimique, 426: 46-47.

[26] Nazar, M., Putri R.I.C. \& Puspita, K. (2020). Developing an android-based game for chemistry learners and its usability assessment. International Journal of Interactive Mobile Technologies, 14 (15): 111-124. https://doi.org/10.3991/ijim.v14i15.14351

[27] Gupta, T. (2019). Game-based learning in chemistry: A game for chemical nomenclature. ACS Symposium Series, 1318: 65-79.

[28] Rahmahani, D. \& Suyoto, P. (2020). The effect of gamified student response system on students' perception and achievement. International Journal of Engineering Pedagogy, 10(2): 45-58. https://doi.org/10.3991/ijep.v10i2.11698

[29] Wolski, R. \& Jagodziński, P. (2019). Virtual laboratory: Using a hand movement recognition system to improve the quality of chemical education. British Journal of Educational Technology, 50(1): 218-231.

[30] Díez-Pascual, A.M. \& Díaz, M.P.G. (2020). Audience response software as a learning tool in university courses. Education Sciences, 10(12): article number 350. https://doi.org/10.3390/educsci10120350

[31] Cuevas-Martínez, J.C., Yuste-Delgado, A.J., Perez-Lorenzo, J.M. \& Triviño-Cabrera, A. (2019). Jump to the next level: A four-year gamification experiment in information technology engineering. IEEE Access, 7: 118125-118134. https://doi.org/10.1109/access.2019.2932803

[32] Sánchez-Rivas, E., Ruiz-Palmero, J. \& Sánchez-Rodríguez, J. (2019). Gamification of assessments in the natural sciences subject in primary education. Educational Sciences: Theory and Practice, 19 (1): 95-111.

[33] Akhmetov, N.K., Nurakhmetova, A.R. \& Sagimbaeva, A.E. (2015). Game training in chemical qualitative analysis. Almaty: Ulagat.

[34] The game "Analytical Lotto". (2020). Retrieved from: https://akhmetovchemicalgame1.netlify.com

[35] Carrillo, D.L., García, A.C., Laguna, T.R., Magán, G.R. \& Moreno, J.A.L. (2019). Using gamification in a teaching innovation project at the university of Alcalá: A new approach to experimental science practices. Electronic Journal of e-Learning, 17(2): 93-106. https://doi.org/10.34190/jel.17.2.03

[36] Alfaqiri, A.S., Noor, S.F.M. \& Ashaari, N.S. (2020). Exploring indicators of engagement: applications for gamification of online training systems. Periodicals of Engineering and Natural Sciences, 8(4): 2096-2106.

[37] Sus, B., Tmienova, N., Revenchuk, I., Bauzha, O. \& Stirenko, S. (2020). Gamification approach to the creation of virtual laboratory works and educational courses. CEUR Workshop Proceedings, 2711: 68-78.

[38] Fediv, O.I., Buzdugan, I.O., Vivsianyk, V.V., Prysiazhniuk, I.V., \& Prysyazhnyuk, V.P. (2021). The role of Moodle software among medical students during distance learning. Scientific Bulletin of Mukachevo State University. Series "Pedagogy and Psychology", 7 (2): 63-69. https://doi.org/10.52534/msu-pp.7(2).2021.63-69 
[39] Moroz, L.I., Dikhtiarenko, S.Yu., \& Andrusik, O.O. (2021). Emotional resilience as a major factor in the mental health of prospective university students. Scientific Bulletin of Mukachevo State University. Series "Pedagogy and Psychology", 7 (2): 118-124. https://doi.org/10.52534/msu-pp.7(2).2021.118-124

[40] Zinchenko, A.S. (2020). Project-focused personnel management approach of higher educational institutions. Asia Life Sciences, 22 (2): 243-256.

[41] Zub, L.O., Roborchuk, S.V., \& Buzdugan, I.O. (2021). Pedagogical theory and personality development during distance learning among medical university students. Scientific Bulletin of Mukachevo State University. Series "Pedagogy and Psychology", 7 (1): 54-62. https://doi.org/10.52534/msu-pp.7(1).2021.54-62

[42] Gardelis, K., Lalos, A.S. \& Moustakas, K. (2018). Development of an eco-driving simulation training system with natural and haptic interaction in virtual reality environments. $13^{\text {th }}$ International Joint Conference on Computer Vision, Imaging and Computer Graphics Theory and Applications, 2: 94-101. https://doi.org/10.5220/0006619500940101

[43] Kohut, O.O. (2020). The concept of integrative development of the personality's tolerance to stress in systemic discourse. Scientific Bulletin of Mukachevo State University. Series "Pedagogy and Psychology", 6 (2): 113-123. https://doi.org/10.52534/msu-pp.6(2).2020. $\underline{113-123}$

[44] Zhanysova, A.B., Kulzhumiyeva, A.A., Nurkasymova, S.N., Yermekova, Z.K., Baydabekov, A.K., \& Sadikova, J.M. (2014). Information technology on the study of mathematics bachelors nonmathematical specialties. Life Science Journal, 11 (6 Spec. Issue): 333-336.

\section{Authors}

Salima A. Medetbayeva is a Doctoral Student at the Department of Chemistry, Abai Kazakh National Pedagogical University, 050010, 13 Dostyk Ave., Almaty, Republic of Kazakhstan. Her research interests are gamification of studying process and computer-aided teaching of natural sciences.

Nurlan K. Akhmetov is a Full Doctor in Pedagogical Sciences, Professor at the Department of Chemistry, Abai Kazakh National Pedagogical University, 050010, 13 Dostyk Ave. Almaty, Republic of Kazakhstan. His research interests are modern technologies as an addition to the teaching of chemistry and methodology of teaching of natural sciences (Email: akhmetov6239@uoel.uk).

Article submitted 2021-06-01. Resubmitted 2021-07-29. Final acceptance 2021-08-01. Final version published as submitted by the authors. 